Botticello, Julie (2016) From documentation to dialogue: exploring new 'routes to knowledge' through digital image making, Visual Studies, 31:4, 310-323

http://www.tandfonline.com/doi/full/10.1080/1472586X.2016.1246351

\title{
From documentation to dialogue: exploring new 'routes to knowledge' through digital image making
}

This article considers the mediating role of digital photography for eliciting embodied and dialogical processes of knowledge sharing and knowledge making in the course of ethnographic fieldwork. Based on research in the last remaining Leavers Lace factory in England, the article details examples of how the visual is linked with the aural, gestural, performative and discursive in attempting to reveal know-how and understanding around machine made lace. The article shows that in spite of multisensory engagements, both knowledge transmission and knowledge uptake remain partial. However, through multisensory means to communicate and comprehend, researcher and participants create new ways of understanding, relating and representing the practice under study.

\section{Introduction}

The aim of this article is to upset the traditional notion of photography as an 'embalmer of time' (Bazin 1967, 14, cited in; Murray 2008,151) and an objective and authoritative form of documentation. Rather, it argues for multiple and partial perspectives on how to understand the entire process of situating, communicating, taking, understanding, and representing through digital images created in the course of anthropological ethnographic fieldwork. The shift is away from discussions on the dominance of a singular, privileged vision of the ethnographer, to the more complex interplay involved in knowledge making and information transfer, in which content, context, relationship and reflexivity are all implicated.

Foregrounded here is the relationality necessary for the images to be produced, based on knowledge and meaning as emergent in the contexts surrounding and including image production. The digital image has a particular place in this specifically at the point of image creation, as the immediacy of the image produced aligns with the moment and context of its creation, and is part of that 'indeterminacy' (Pinney 2002, 82; Star 1996, 303) of knowledge and meaning making as part of a relational process. The reduction in temporal distancing between image making and image sharing creates transparency and immediacy in the relationship between participant and researcher that extends the relationality evident in the encounter of analogue photography. In arguing this stance about the dialogical production of images, through reference to contexts of creation as well as actual or anticipated audiences, this article contributes to current scholarly research (Bell 2003; Edwards 2003, 2005; Herle 2009; Peers and Brown 2009; Woodward 2008; Wright 2009) on the mediating role of photography, amid other forms of multisensory connection, and the dialogic element of knowledge sharing.

\section{Background - Nottingham lace manufacture and Cluny Lace}


This research was undertaken for Nottingham Trent University, through a funded AHRC/EPSRC 'Science and Heritage' programme: 'Nottingham Lace: Capturing and representing knowledge in people, machines and documents'. The project focused on historic lace making - Leavers Lace - and on trying to grasp, capture, preserve and represent the 'intangible heritage' and various knowledge bases that go into its production. While mechanised, the knowledge to make Leavers Lace is variously embodied in people, embedded in machinery and encoded in documents.

Nottingham and the East Midlands have a long history of lace and hosiery making, dating back several hundred years. During the industrial revolution, lace and hosiery making were mainstay industries in the East Midlands, where several firms housed over 26000 lace machines. Today, this same area houses just 16 machines and these are located in a single factory, Cluny Lace, in Derbyshire. Cluny Lace is a family owned business, whose involvement in lace production in this part of England can be traced back for at least nine generations (personal communication, Charles Mason, 8/8/2013). Through the early and middle parts of the twentieth century, Cluny Lace kept pace with their British competitors, firms such as Birkin, by adding to their mechanised repertoire with modern and faster machinery.

As the twentieth century wore on, however, the manufacturing industry in Britain substantially declined and the manufacturing base shifted from Britain to East and Southeast Asia, where it remains today. Recognising that Cluny Lace could not compete in this market on price, in 1999, managing director Charles Mason decided to progressively sell off their modern lace machinery, and focus their business model on an older form of lace production, Leavers Lace. Industry competitors, such as Birkin, who relied on large commissions from big UK department stores for underwear and household lace, could not maintain their domestic businesses when their regular buyers aimed to reduce their own costs by buying lace manufactured overseas. Trading on tradition, quality and Englishness, Cluny Lace maintains its place, albeit precariously, with just 20 staff, including management, in the global marketplace by marketing its lace for elite buyers, with recent notable commissions for Catherine, the Duchess of Cambridge's wedding dress in 2011, and for inclusion in Burberry's collections from 2013.

A process devised during the industrial revolution, Leavers Lace (named after John Leavers who invented the machine in the early 1800s) imitates handmade. It is made on machines that mechanically twist two sets of threads into a net structure. Leavers Lace manufacture is much more labour intensive than modern machine lace manufacture. A modern lace Raschel 'knitter' might oversee up to 10 machines at once, whereas a Leavers Lace 'twisthand' could manage up to two machines at most, due to the constant attention required to keep the machines running amid thread breakages, beam and carriage replacement, tension management and pattern implementation. As one lace maker humbly reveals when moving from being a knitter to a twisthand:

It's not something that you can just walk into and up in five minutes; be nice if you could! It is a skill. When I first came on this side [from Raschel knitting], Charles said, it is a skilled trade, not just [a] plod on. It is a skill, the weighting of the beams, bars, everything else. (MJ, 26 March 2013) 
At Cluny, one twisthand operates one machine at a time, with support from other skill specific workers, who replenish the materials consumed in production orundertake mending and finishing once completed. While this makes lace production into a factorywide collaboration, the skill of production coalesces in the work and know-how of the twisthand.

Most of the twisthands at Cluny have spent 50 years in the Leavers Lace industry, many having worked for Cluny's competitors before finding work at Cluny, as the firm that has outlived all others in England. While approaching or even in retirement, workers are keen to continue using their specialised skills. Because of the uncertainty in the manufacturing climate in the United Kingdom, Charles Mason refuses to take on any young apprentices to the trade, so the workers have no direct 'heirs' to pass their knowledge on to before retiring. Thus, the economic rationale about current viability of the industry is at odds with the cultural rationale of knowledge transmission for future production.

\section{Methodology}

The research was factory- and work-based, operating on a phenomenological principle that work-based knowledge is best understood when the actual work is being undertaken. 'Whereas theory thinks the world', in a phenomenology of practice, 'practice grasps the world' through 'relational, situational, corporeal, temporal [and] actional' (von Manen 2007, 20) means. The methodological approach of chaîne opératoire is also insightful. At its simplest, chaîne opératoire denotes the sequence of production (Martinón-Torres 2002, 31; Schangler 2005, 25), articulating each stage and placing it in an order. However, as importantly, chaîne opératoire also connotes an approach, an interpretive methodology in which accounts are taken of the 'material patterning of technical acts and the sociopolitical relations of production accounting for them' (Martinón-Torres 2002, 33, citing; Dobres 1999, 124).

While lace making derives from a sequence of actions, how these actions are enacted, based on particular knowledge bases, differentiates workers' histories and skills. I experienced what each worker does, and how that contributes both to the ongoing running of the machines as a cyclical process of work, as well as to the linear process of producing lace to leave the factory for sale. Although lace production has been streamlined in the factory as a routinised process, making lace manifests amid the challenges of thinking through and working out problems, inevitable in any act of making, but more often than not, hidden when contemplating the object of production as a complete entity. The final object can belie (c.f. Schangler 2005) its existence as the sum of multiple inputs, from different minds, materials and modalities, which have come together to generate this outcome. The images I took attempt to deconstruct the final product into its constituent inputs. However, by focusing on the sequence, I came also to understand the complex human-machine (and human-human) connections and 'interactions' (Star 1996) taking place across the factory in the making process.

As the ethnographer, I used a multi-faceted methodology, including talking to workers as they worked, observing what they did, trying it myself, recording semi-structured interviews with them in front of their machines, as well as using photography and film (e.g.: Twisthands at the Deadstop 2013). I also engaged in workers' personal histories of lace making, by looking through worker's own lace pattern albums, watching videos 
fellow factory workers had made, and reading personal notes, poems and stories written by lace workers, collected throughout their working lives. This methodology reveals the 'integrated webs' (Martinón- Torres 2002, 35), not only of daily production and the social milieu in which this is embedded, but also with me, the ethnographer entering into their work place and engaging in visual and verbal dialogues to understand what they do.

Although a large quantity of 'capturing' equipment - notebooks, voice recorder, still camera, motion camera, tripod, various lenses, battery packs - accompanied me to the field, my first couple of months were dedicated to getting to know the work flow in the factory, each worker's physical and chronological place in that flow, how they found themselves in the last Leavers Lace factory in England and what vast knowledge they had not only about their own particular skill set, but also their co-workers' jobs, and the industry more generally. For this methodology, I participated in the daily rhythm of the factory work, oftentimes getting a bus from Nottingham at 6:30 am to arrive in Derbyshire, ready for work by 7:00 am, in line with the workers.

At the outset, there remained an underlying idea in my mind and that of the research team that through filmic and photographic media, technique, process and skill would be revealed and once visually documented, could then represent these to others. This reflects the observational approach redolent of early twentieth century anthropology, which operated under the assumption that to 'watch someone is to learn something about them' and in doing so to generate 'knowledge that can be later analysed and converted into intellectual capital' (Banks, 2001, 112). Due to the complexity of the production processes and the need for trained eyes to be able to 'see' in any meaningful way any aspects of what was 'captured', the visual images taken and their chronological sequence are less objective than this. Rather they chart my own learning curve and dawn of understanding on praxis, in the documentation of the embodied and embedded knowledge and routinised processes of work. What was captured was not the workers' know how, but the process of working out ways for the lace makers to share their knowledge in such a way that I could understand some of it and document it.

Still and moving digital images were tools that facilitated this conversation, enabling a shift from my ignorance (Dilley 2010, S179) towards an understanding of a practice, if not actual skill, as sufficiently grasped; this was further clarified through the immediacy of viewing and through further explanatory dialogue.

\section{Visual theoretical framework}

Many contemporary writers on image based and ethnographic analyses argue for a multiply engaged approach to the production of images and their interpretations (Banks, 2001; Favero 2014; Herle 2009; Pinney 2002; Pink 2003, 2007, 2011, 2012; Woodward 2008). Banks argues that 'social knowledge is a processual aspect of human social relations' and that to undertake social research well, the researcher must submit herself to engagement and of knowledge making with her participants (Banks 2001, 112). This was one of the main purposes to the research - how to understand the workers' know-how, so that I could pass this on to others. In the process, it was not just me watching and learning from them; the workers had to learn how to transmit some of their knowledge to me, who could then, through my own understanding, begin to represent it to others. 
In her appraisal of Layard's images of Malakula, Herle comments that these are not just a product of fieldwork, but 'are part of the process of fieldwork, summoned into existence by the complex intersubjective relations between Layard and his informants and hosts' (Herle 2009, 241). In a similar way, the lace workers and I collaborated to coproduce a new knowledge base, on how to capture and represent aspects of their work practice which could be understood by non-specialist others. The twisthands were at great pains to show me what to see and to tell me how complex their work was, by reiterating its difficulty in their narration. Having been researched a number of times before, for local documentaries (The Lacemakers, 2013), by oral historians for depositing in local archives, and by high street producers using Cluny Lace in their collections (Anon 2015), some of the workers were very well versed in communicating what they do to different audiences. The lace makers and I engaged in 'multiple perspectives and negotiations' (Star 1996, 304) to communicate and create affordances to understand and be understood.

Due to the disparity in competency over understanding their work processes (theirs great and mine very little), this knowledge transfer was partial in its undertaking. However, as Haraway intervenes, all knowledge making is partial and relational. This is not a weakness, for it is in the interstices of inquiry that understanding unfolds. As she states, in the 'epistemology of partial perspectives [...] the possibility of sustained, rational and objective enquiry rests' (Haraway 1998, 194). While such translations are 'always interpretative, critical and partial' (Haraway 1998. 197), it is in this partiality that the co-construction of knowledge can occur. Lack of understanding makes the process of interaction a dialectical one; it 'guarantees potential knowledge' (Dilley 2010, S177) as an outcome of the interaction and ensures that neither time nor process are embalmed (Bazin 1967, 14) but are undergoing constant creation.

The knowledge making process was dependent upon each of our abilities to communicate and comprehend, discursively and visually. For the lace workers, this was through words and in practical explanation and demonstration; for me, this was through my questions, my notes and my photographs. As Jorgensen $(2013,91)$ points out that while there has been a recent interest in technology as a non-discursive practice of knowledge transmission, she takes issue with the implication that 'tacit' knowledge does not need language or literacy, challenging the assumption that 'technology is nondiscursive knowledge' (Jorgensen 2013, 91). In response to my question of how he learned his trade, one twisthand replied:

Most of it was word of mouth, from other twisthands that you were put with, when you are an apprentice. [...] We learned most of what you do as a twisthand on the shop floor. All aspects of the job. You pick up most of it there. [...] So all this background knowledge, it is not written down, it is all passed by mouth' (IP, 12 April 2013)

This suggests that the passing on of information and knowledge did indeed have a discursive as well as a demonstrative aspect to it. Following in this tradition of passing on, in my fieldwork on the factory floor, we engaged in multiple means of transmission, including discussion, demonstration and visual representation - as hand drawn pictures 
and as digital images - to communicate and confirm each another's understanding (for me, of their work processes and for them, of me grasping their work processes).

My enquiry into capturing their knowledge through images and via discussion can appear full of hubris about the possibilities to see, understand, do, replicate and communicate the skilled work of others. It entailed a multiple stage process of acquiring and passing on; for them, how to reveal their practice, and for me, how to understand sequence and anticipate actions in (re) constructing (MacDougall 2005, 4) this record of our transactions in images and text systematically into an order of practice.

The rest of this article will explore in more detail the relationship between image making, knowledge making, and master and novice (in this case, ethnographer) in passing on and trying to explain embodied knowing. It will also reveal the relationships developed between my participants and myself in this. While my relationships could not be photographed directly, as I was behind the camera and they were in front of it, some of the images generated reveal, in their contextual analysis, an intimacy between researcher and participant (Herle 2009). Some of this closeness is technical. I used a 50 mm lens, often with a 1.4 aperture on a Canon SLR digital camera. While enabling me to work in low light, it necessitated closeness to the 'subject' due to a limited depth of field to capture and focus on what I was intending. But the technical demands of my equipment were secondary to the necessity of proximity to the lace makers as they worked, as regardless of me taking pictures, it was this relationship, between the workers and me, which enabled a close appreciation of their practice. My partial perspectives, of incompleteness, soon also became a partial perspective of gaining a liking for and appreciation of their work.

Most of the images were taken in explicit collaboration; where I asked them to slow their processes down so that I could capture these in stills, stop framing the work to understand its particular stages. This illustrates succinctly how partiality here as attention to the incomplete leads into the inquiry of discursive and interpretative practice. These slowed down movements precipitated further dialogue over what they were doing, and their interest in whether the work was successfully captured on camera. The camera then, while in my hands, became a medium for them to pass on through instruction, and through its visual manifestation, confirm it had been adequately captured.

In relating these two aspects of documentation and dialogue, I include snippets from fieldnotes as well as selected images to bring into play this methodological collaboration. In the ethnographic context of its creation, the digital image is an immediate occurrence, which becomes a point of discussion at the moment of its creation. By including the texts together with the images, I hope to recreate some of the dynamism that was part of the fieldwork experience. By contrast, in this article, the images have now become fixed, no longer part of a dynamic process of production, and once in this situation, as Barthes comments, this 'makes it difficult to speak about photography' (Barthes 2000,6), as the content of the images tends to command attention. My aim, however, is to draw attention to photography, as a process and product of relation, From documentation to dialogue 313 revealing contexts of creation, as well as being a bearer of content and meaning(s). To this end, I use images as tools to reveal my methodology as both self-directed and led by others, as ethnographic choices 
and limitations about content and detail, as illustrations of visual theory in ethnographic practice, as narratives about production sequence and also as images to be appreciated immediately and aesthetically (MacDougall 2005). These multiple positionings suggest how images continually build on their own repertoire of significance (i.e.: Peers and Brown 2009), dependent on who is looking.

\section{DIRECTED SEEING}

Banks states that most field workers approach photography in their research with some intention of documentation, 'to remember the experience, to show others how things looked, to record things that were too complex to be described in a notebook' (Banks, $2001,114)$. Banks' final point is most relevant, as grasping the way a pattern is implemented on the machine through threading and machine adjustment was immersed in a depth of knowledge beyond the scope of a novice to understand in just a few months of contact. Rather, at worst, my voice recordings document the explanations they gave me, but not what I understood from these. It can also be argued that my photos could equally leave me ignorant, as a 'blind' (MacDougall 2005, 3) shot of the machine encompassed so many possible points to consider, I likely captured something meaningful in the shot, but did not possess sufficient understanding of these processes to see what was being represented (Figure 1).

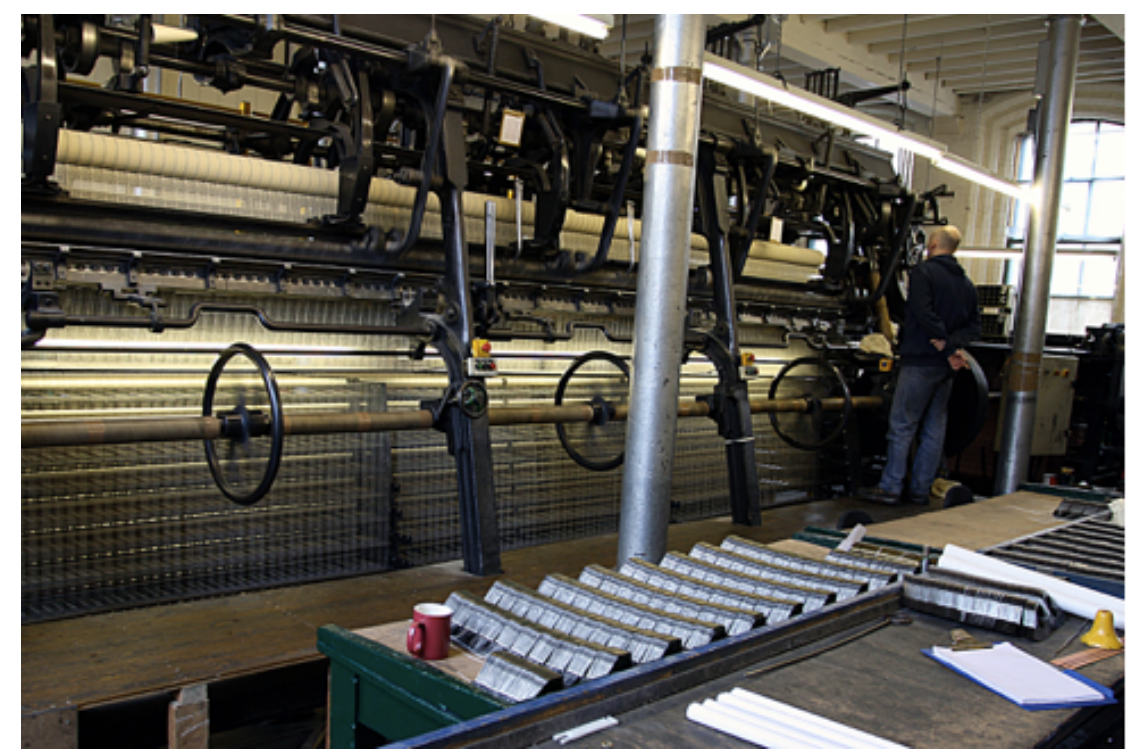

FIGURE 1. Leavers Lace machine.

To help me out from this difficulty, of hearing but not understanding and looking but not seeing, participants attempted to show me where to look, how to look, what to see, what to hear, what to understand and furthermore, what to photograph so that I could 'see' and 'grasp' aspects of what they know. The normative definition of the research relationship of an 'unconscious informant' being scrutinised by a more 'informed' researcher, in which the 'subjects [...] are not themselves full participants' (Suchman 1995,61 ) is redefined 'when the participants direct the photographer' (Woodward 2008,863 ), reversing notions of authority in the investigation. As Pink remarks, how 'knowledge is produced during the research [is] the outcome of the relationship and negotiations between the researcher and informants rather than the former's objective observations of the latter' $(2003,182)$. The lace research extends this model, not just of negotiating image taking, but being specifically guided in what to look at and how to 'see'. 
One of the ways they did this was by taking me through basic processes. Thousands of threads are used in lace production and these need replenishing at regular intervals, ideally before the threads run out completely. At many points throughout the day, the twisthand will switch off his machine, and he will be at the back of the machine, tying in new threads from replenished beams. Wherever possible, the twisthand does not let threads run out; rather, current threads become the guides for the new ones to be brought through the machine. All beams are not changed at once, but only when under threat of running out of thread, so this process of stopping the machine and tying on a new beam is a regular occurrence.

MJ, aged 46, is a twisthand who has been working inLeavers for 10 years, having shifted his work within Cluny after it completely closed its Raschel lace production. His 10 years in Leavers is considered a relatively short time in comparison to his coworkers,and his relatively 'new' status is something both he and his co-workers comment on, albeit favourably in terms of his ability to pick it up and produce good work. MJ took me through this beam thread replacement process. Working from the back, he painstakingly tied new threads to ones already in the machine (Figure 2). Once completed, he returned to the front of the machine and started it running again. After several minutes, he directed me to look for the new threads he had tied in to start appearing at the front of the machine, where old and new threads had been tied together (Figure 3). Seeing his ties progress through the machine, drawn from the back, pulled through the front and finally woven into the lace, clarified one aspect of the lace making process, of thread movement and harnessing machine action for thread replenishment.
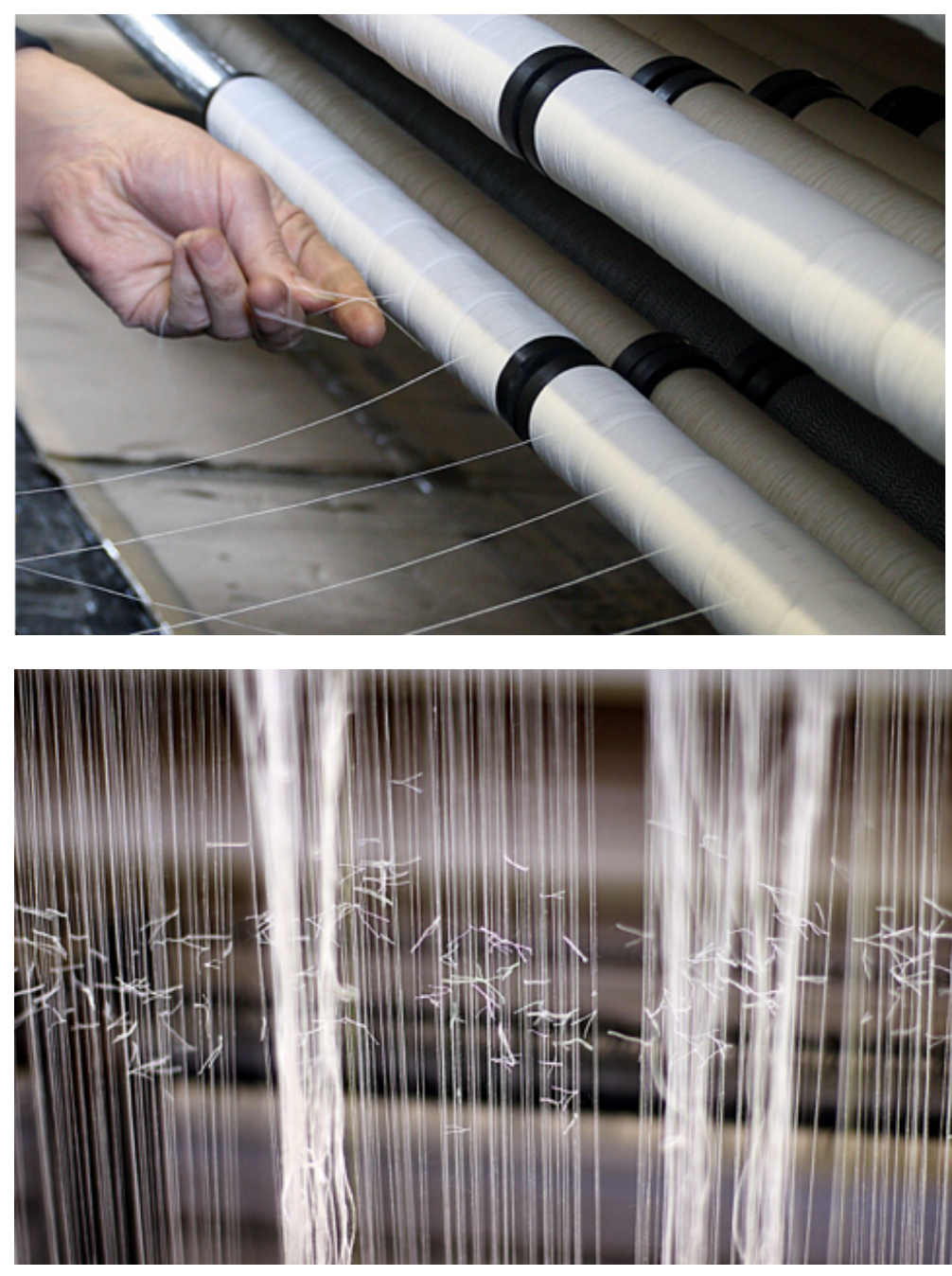

FIGURE 2. Tying new threads to old threads already in the machine.

FIGURE 3. Knots linking old and new threads. 
In moving from keeping the machine threaded to controlling for the idiosyncrasies of old machinery, we move to IP, aged 64. Trained at age 15 at Birkin, a competitor factory, IP has been working in Leavers Lace manufacture for 48 years. After Birkin closed down in 2005, he trialled a brief stint in China to embrace the manufacturing shift to South East Asia. Not fulfilling his expectations, IP came back to the East Midlands to work for Cluny in 2006. He talked me through the challenges of differing tensions among thousands of carriages that house the base threads, wound onto brass bobbins, around which the lace is twisted. Given that the procedure and the machinery are both historical, dealing with a lack of uniformity is part of production. As he says, 'the trouble is we're working with very inferior materials now, everything's not brand new; everything wears' (IP, 12 April 2013). The tension in the carriages impacts on the tension in the lace; tighter ones pull the threads more tightly together, while slacker carriages leave the threads farther apart, creating an overall lack of uniformity in the lace made.

You'll find when you shake the carriages - you've seen that? (Figure 4) ... That's a slack one. If you've got too many slack ones against too many tight ones, then you get an abnormal wale, [where] it pinches in or it slackens out. The wale is the difference [...]. You see that thread there, coming straight down and the one next to it that's coming straight down, well in between that's called a wale (Figure 5). And the thread that's crossing over, either side, that's making the net [lace]. If you get some [carriages] that are very slack that are crossing over, you get a wide wale; on the other hand, if you get a tight one there, you get a narrow wale. (IP, 12 April 2013)

While unable to adjust the tension, the twisthands can test the carriage/bobbin units for their particular tensions, through shaking them out with a 'technique of the body' (Mauss 2007), and intuitively grading the tight, the slack and those in between. Once this is done then they can decide how to place them in the machine to yield the best result in the lace. In trying to help me understand this process, a combination of discussion, directing looking and impromptu performance were employed, affirming the multi-sensory approach in knowledge sharing.

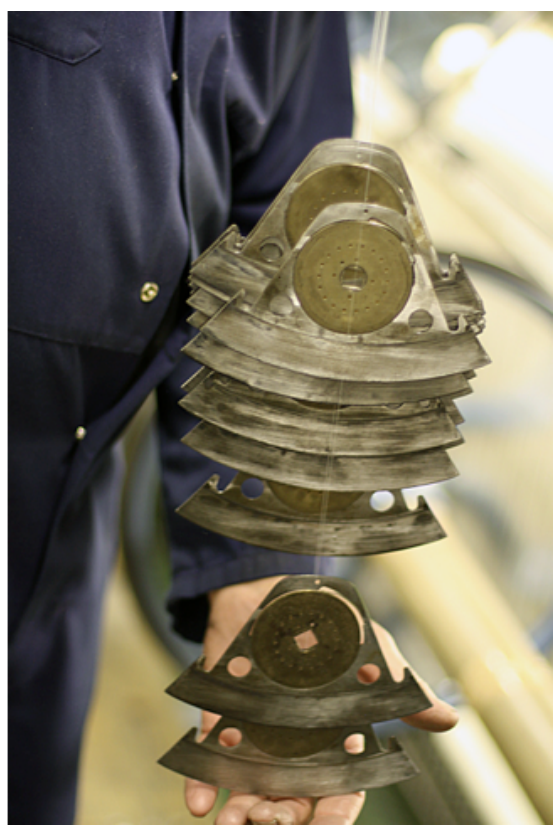

FIGURE 4. 'Shaking' the carriages to discern relative tensions. 


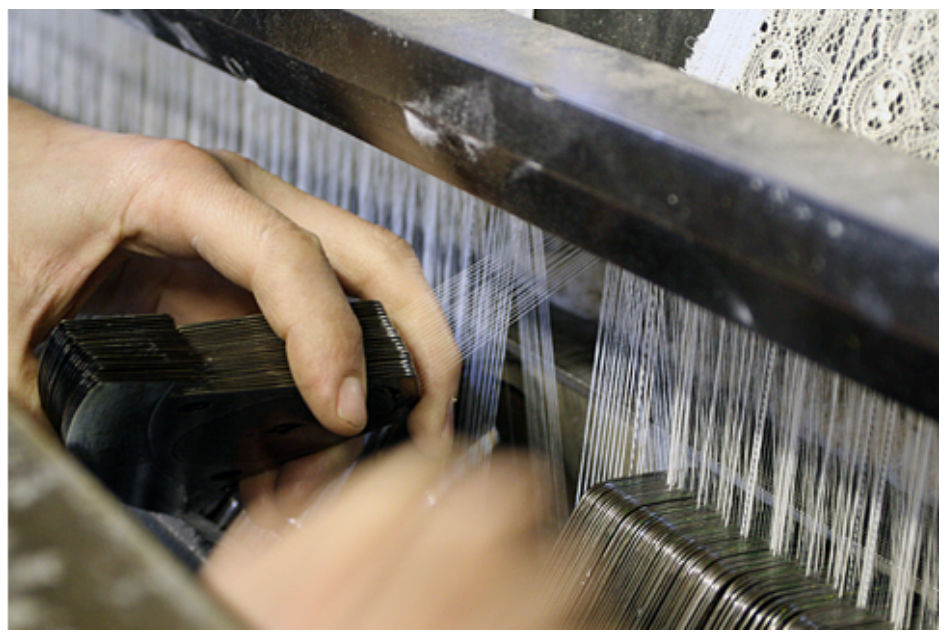

FIGURE 5. Variable distances between the threads in the machine.

On another occasion, I was situated with a different twisthand, PS, who was also aged 64, with 49 years in the trade and had come over from Birkin to Cluny, but oneyear earlier than IP, in 2005.1 PS tried to explain to meabout how a particular lace pattern was configured by the machine movements. There were two points he wanted to make about the workings of the machine in connection with the construction of a given lace pattern. One was how it looked on the machine, the other was how the sound of the machine corresponded to this visual. The pattern he was making had a threedimensional aspect to it, with little raised baubles as part of the design. Here, I refer directly to my fieldnotes to explain.

When asking him about this particular pattern, one of those with elevated loops in it [PS tells me that], the quality wheel disengages to allow the pattern to build up without pulling the lace [through the machine]. [Stopping the machine entirely] he puts his hook though to show me (Figure 6). (fieldnotes, 10 May 2013)

Situated again at his work station later that month,

He tells me to look along the length of the machine and I will see, like little noses on the points, the elevated hoops being made before the quality wheel reengages, and [pulls] the lace [through]. [Then] he walks over to the jacquard and says that even this goes quieter at that point, when the elevated loops are made on the lace. (fieldnotes, 23 May 2013)

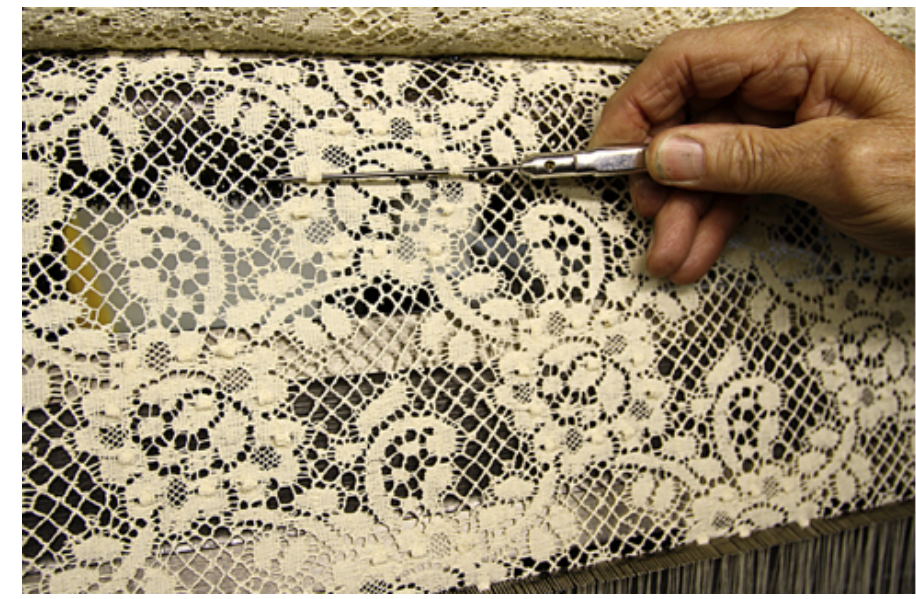

FIGURE 6. Baubles created in the lace. 
Early in the research, the factory owner, Charles, 'spoke about how the men who work in the factory are able to listen and hear, not just see, that the machines are operating well and the [materials] are going through as planned' (fieldnotes, 26 March 2013). His comment revealed the embodied aspect to the lace production, where all senses are engaged, not just the visual (Pink 2011; Pinney 2002). However, this insight remained theoretical at the time and only came to clarification at this moment when PS linked the visual and the aural with the mechanical.

For them, directed seeing was about teaching; for me, it offered a particular opportunity to grasp aspects of the lace making process, reducing the complexity in these isolated instances into comprehensible snippets. While these wisdoms would not enable me to undertake such production myself, following Ryle (1949), I remained in a state of 'knowing that' versus 'knowing how', these more than visual instances and my digital recordings ensured that I had 'got it', at least in part, and so added to my repertoire of the multiple processes and complexities involved in making Leavers Lace. It also reveals how these three twisthands are differentiated from one another in terms of what they know and what they feel capable of trying to convey to me, from the more simple process of demonstrating how tied threads move through the machine to more complex aspects of sorting out thread tensions through actions of the body, to being in synaesthetic (Mitchell 2002, 170) harmony with the machine as it works.

\section{FROM UNCONSCIOUS TO CONSCIOUS COMPETENCE}

This (Figure 7) summarises in one image the embodied knowledge of a given worker it is of IP's eyes focused intently on the threads, his hands responding to the view and the demands of his immediate environment and to the directions his mind is giving, based on his tactile and visual evaluations. Here what can be seen is the triptych of embodied knowing, of a 'neural network of eye-brainhand' in which 'touching, gripping and seeing [...] work in concert' (Sennett 2008, 153). Sennett argues that craftsmanship is a practice within each individual (Sennett 2008,9), albeit as the result of an education as a particular craftsperson, which manifests in his or her implementation of skilled work.

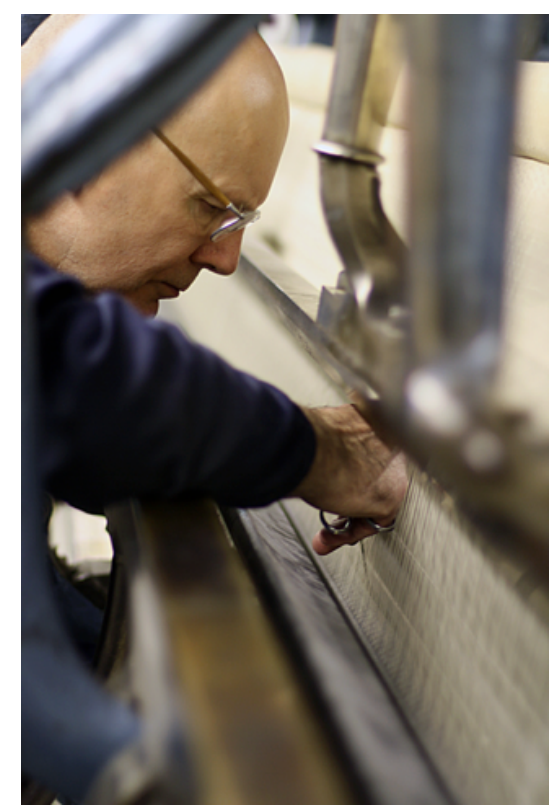

FIGURE 7. Hand-eye-mind complex in action. 
The aim here, however, is to move beyond their competence in embodied knowing to a competence in passing this knowledge on. How to represent their work was an underlying question for my participants and for myself though we each had different aims we were pursuing. They were trying to teach me aspects of what they know in a manner and to a degree that I could understand, and I was trying to comprehend these parcels of knowledge to the extent that I could understand them myself and then pass these representations on to others. For them, there needed to be a shift from 'unconscious competence' to 'conscious competence', where 'both learners and teachers' must understand one another as 'a located participant' (Lave 1996, 158) in this learning and teaching exchange.

Significant moments occurred when workers commented directly on their transmission processes. On my first research day in the factory, I decided to spend time with MJ, asking him very basic questions about the machine and what the threads and different machine components do. I was completely green and apart from a very general grasp that twisted threads progressed through a machine to eventually make lace, I needed more particular instruction to see how. MJ himself had learned the trade relatively recently from the current foreman at Cluny. He recalls:

I was working with him for about 6 weeks, and he was showing me bobbins, carriages, beams - I had to put the thread up - tie the beams out. Basic [stuff]. I was following him around, whatever he was doing, I was there watching him do it and he'd say, 'your turn'. That was my introduction to the Leavers side. (MJ, 26 March 2013)

His own instruction was a matter of tailing this foreman around the factory, watching and doing very small tasks himself. He had never had to teach anyone himself. MJ shared with me that it was a challenge to speak about what he was doing while he was doing it, as it forced him to think through his work mentally in order to be to able to explain and unpack it. On the one hand, it could be argued that it was a challenge to transform his embodied knowledge into discursive, and representational, forms. As Schon states, 'skilful action often reveals a "knowing more than we can say"'(Schon [1983] 1991, 51), because it is difficult to verbalise tacit knowing. However, on the other hand, following the chaîne opératoire approach, although one can see a mind at work 'in the sequence of technical gestures' (Malafouris 2004, 60), this must not preclude the notion that creative processes are 'temporally emergent and dynamic products of situated activity' (Malafouris 2004,60), in which telling others what is happening is more complex as what is happening is determined in the moment. For MJ, to extract how to do something from his tacit understanding of working this out, with the further complexity of relating this process to me at my level of understanding, was a big challenge. Teaching me seemed to be the catalyst for reflexivity on his practice and his ability to be able to distance himself from his embodied knowing and both translate and reduce some of his working processes into discursive forms.

A more experienced twisthand, IP, also had to reflect on his instruction to me, though for different reasons. A natural conversationalist, transferring his knowledge and processes into words did not seem problematic; further, as he had been interviewed numerous times, he was also quite comfortable talking about himself and representing his practice. Which words and to what depths the 
concepts he wished to reveal, however, presented the greater challenge to him. As recorded in my fieldnotes, in the middle of a discussion about his work, IP stopped suddenly and asked,

'Am I confusing you?' He said that when speaking to someone, he has to gauge the potential level of understanding, so that they can communicate to reveal some aspects of the process. If someone technical comes in then, they can talk at a different level than to someone like me, who is just gleaning the process. (fieldnotes, 18-19 April 2013)

There is mediation ongoing between sharing their knowledge and the ability of the recipient to comprehend what is being explained. You cannot just tell someone what is going on, without taking into account current ability to receive and process this information. Participants mediate their knowledge relevant to the situation. As Star notes, 'knowledge itself is indeterminate. This indeterminacy arises because the meaning of knowledge is given in its consequences, in a community of listeners, not in it's a priori analytical specification' (Star 1996, 303; italics original).

The image at the beginning of this section reveals the potential for, willingness of and barriers to passing on. One of the meanings this photo reveals is the hand/eye/ mind complex; it likely reveals other meanings to different people, depending on what they see. The image also reveals a relative closeness between the photographer and the twisthand, at least in terms of physical distance to take the shot, but also in terms of comfort to be able to compose the shot prior to taking it. The barriers arise in the passing on of what is unsaid in this documentation of enacted thinking and seeing, and if something were to be said, to what degree might this be understood?

As evidenced here, limitations reside both with the twisthand and with the ethnographer in the process of communication. At times, the twisthand wishes to share his know-how more fully but he must reduce this into simple terms, verbally and performatively. This may be so that the novice can grasp aspects of the process; it may also be because the twisthand cannot adequately express his embodied understanding. In either instance, the complexity of the interconnection between people, things and images suggests that knowledge itself is relative to the situation of its making and remains partial in its transmission.

\section{PREHENSION ... AND POSSIBILITY}

A few months into the fieldwork there was a pattern change and it was decided that I should participate in this. Throughout the fieldwork, I was often told I should be around for a pattern change, to 'get a feel for the practice' (Bourdieu 1990, 66). In preparation for this event, one twisthand set me a task he felt I could manage.

IP has asked me to help him, so that I can learn to thread, especially as [the pattern change] will require untying those threads currently tied down onto the sley (Figure 8). Today he gave me a trial run, in that he broke a thread, tied on a new one and asked me to put it up. He pulled it through the sley himself, said he'd chosen an easy one for me, and told me that the position of the thread matched that of those in the same position on the breadths either side. He left me with his hook and the thread to figure it out. Earlier I had seen him counting 
holes in the bars so I [...] did the same. I tried to feel the thread up to where it passed into the bar, realized the threads are fed through the back and then are pulled though to the front, and again, copying what I had seen him do, put the hook in up to the handle to mark the place and then bring up the thread. I was worried I would break more threads as the hook entangled with other threads, but in the end I found the right bar - the front one - and counted across, and pulled the thread through. [IP] came back as I was pulling it with the hook and he said that the flat bit on the handle indicated which direction the hook was facing and so I pointed the flat bit toward me, and [thus] the hooky bit, and so was able to thread the bar. IP checked it - he also counted along to do so - and said I was right. (fieldnotes, 10 May 2013)

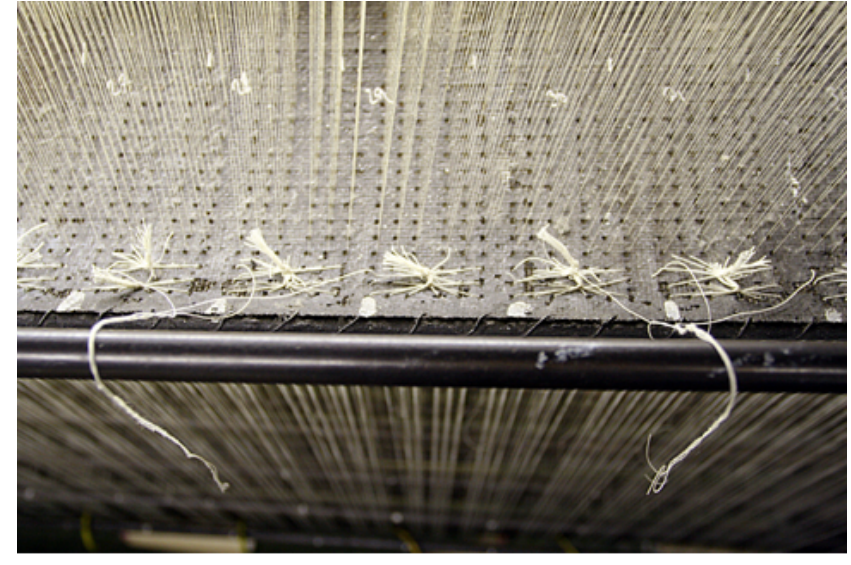

FIGURE 8. Knotted threads tied onto the sley.

Here I attempted to translate from vision into practice, moving from a sense gleaned from eyes and mind, to Sennett's hand-eye-mind complex of doing and anticipated action, based on experience. I did successfully manage to put up a new thread where the broken thread was, amid my fears of causing more damage in the process. While my actions were premised on imitation, of having watched, photographed and been talked through the practice; in executing them, I had to navigate my way via a series of decisions I had to make myself. Sennett uses the term 'prehension' to describe the anticipation we have towards understanding something, amid incomplete information in which to achieve it. Similarly Schlanger argues that in the chaîne opératoire approach, there are no complete mental maps drawn, but rather 'a generative interplay between mental and material possibilities, involving planning and decision making as well as more tacit or routine practices' $(2005,28)$. In my threading moment, I had to draw on the learning I experienced in the factory environment, coupled with other learning experiences I had previously had with threads, hooks and holes, to think through my sequence and construct a process.

The images employed here to tell this vignette are not of my own experience of threading, but of ones I took documenting the workers' undertakings, in the course of the fieldwork. In these instances, while these earlier shots of their work taught me, in part, what to do, they have now shifted, through my specific interpretation, to become narrative components to illustrate my journey to knowing. Furthermore, as fieldwork progressed, I started anticipating which gestures implied what actions and what would be useful to capture - such as when the worker puts the catch bar down meant the imminent start to the machine moving or when a large quantity of lace on the upper 
roller meant that the lace web would be pulled off soon - and waited for these events to happen. This awareness put me into a position of being able to direct my own vision, having 'learned to see' (Bell 2003, 120) after several months of looking.

Yet meaning and being need not be an either/or choice. Referring back to Figure 8 specifically, what was an attractive knot on a black background early in my fieldwork remains aesthetically significant, despite its physical and conceptual unravelling to become a specific set of threads, each group corresponding to a repeating part of the pattern, which, during the pattern change was completely undone and reincorporated into the lace web. As MacDougall $(2005,6)$ suggests, my earlier depiction was predicated on an enchantment with being, in the pleasure of looking at and appreciating; having untied the knot, I also got to appreciate its meaning as placeholder for the next pattern. For the purpose of this fieldwork, the latter seemed more important; however, the beauty of the image both upholds my unfolding partialness towards Cluny Lace and withstands my partial understanding of what the lace makers know of its construction.

Finally, on this partiality in the sense of ignorance, although I had gained an understanding of workflow and process, due to lack of embedded time in practicing their work, I could not undertake more of these actions and meet with equal success. As discussed earlier, IP had previously talked me through one of the processes for checking the carriage/ bobbin unit by 'shaking' them to determine the relative tensions of the bobbin threads. A further task, of holding a handful of carriages up to the light (Figure 9) in a process called shining, aims to provide a further visual check for irregularities in the relationship between the bobbin and carriage, before slotting the carriages into the machine (Figure 5). IP showed me some slack bobbins in their carriages; these had both bobbin yarn and beam thread sticking out of them, as these were so wide, they had cut down the vertical threads in their motions, instead of passing between them.

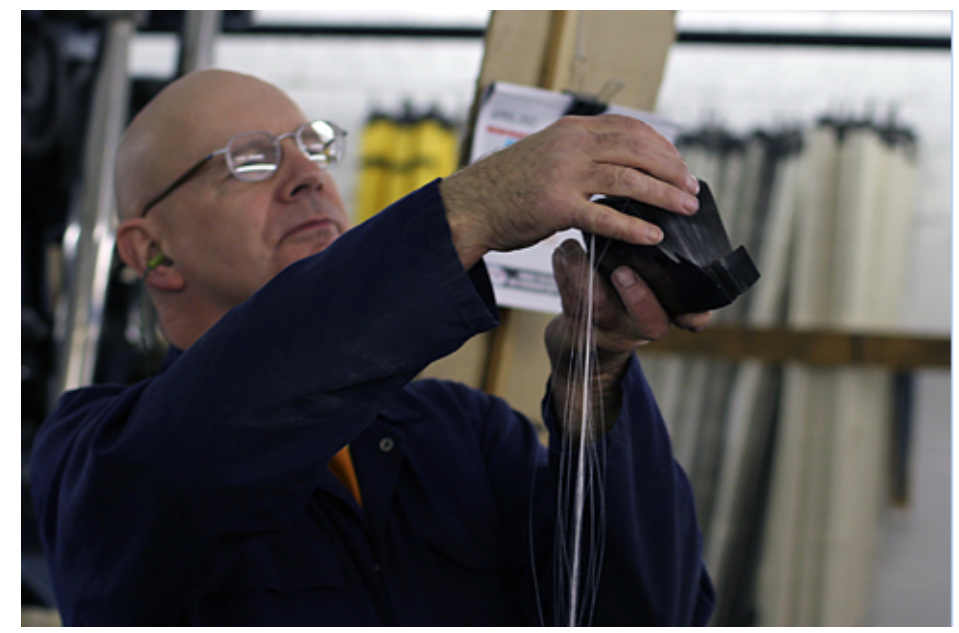

FIGURE 9. 'Shining' the carriages to look for irregularities.

He then tried to show me the difference between a good and a bad bobbin, each set within a carriage, through the shining process. He put two together, held them up to the light, and said that the bad one would look darker than the good one. He passed the pair to me and I looked through them and tried to see what he wanted me to, but I could not tell the difference between them. He took a further step and drew me a little sketch of what I should perceive, to try and show me, in a directed fashion, what to look for. Although I recognised his action and why he was doing it, my eyes could not spot the 
difference. This returned us both to the realization that while I was able to achieve some basic tasks in the Leavers Lace trade, and could narrate and represent in the images what I had grasped about some of the processes, my true colours as novice glaringly remained.

\section{CONCLUSIONS}

The creation of digital images in fieldwork and the knowledge potentials these images contain, at that moment and after, are based on the participant-researcher dialectic. This is a collaborative and generative act. While this may be hidden when considering a given image, as Favero $(2014,167)$ argues, like Herle (2009), one needs to look beyond the frame of an image to see the 'context, relations and materiality, and hence the world, surround[ing]' it. As seen in this article, my images transitioned from blind shots to becoming more seeing-centred, as I came to understand more of the processes I was attempting to represent through being guided in where to look and what to see. Further, as I understood more, not only could I direct my shots by responding to gestures and clues in the environment as to what might happen next, I could also revisit earlier images and see in them content and context I could not grasp earlier on. As Pink argues, the meaning of an image will shift depending on the 'different eyes and audiences in diverse temporal, historical, spatial and cultural contexts' (Pink 2007, 68). At one level, the different eyes gained throughout the fieldwork were my own, augmented through understanding the practice from the sum of various parts - through looking, seeing, representing, hearing, listening, discussing, questioning, trying, succeeding and failing created over the research period.

However, as I never attained a complete understanding of the lace production processes, at another level, my understanding of my images and their content continues to remain partial - that for me they reveal less than for those with more skill and insight can understand from them. These images nevertheless remain part of that dialogic collaboration between researcher and participant, revealing and, at the same time, resisting meaning. Given the multiple meanings of content and context any image may represent, what I have assembled here is the narrative of collaboration and its impact on representing a practice. This narrative became my 'function of resemblance as a route to knowledge' (Ruby 2000, 7, cited in; Pink 2003, 181) and tells a partial tale of what the workers know, and a more complete tale on the partiality (in both senses of the word) of my knowing and how this impacts on my ability to see, and my choices to classify, order and assemble the images into any particular story.

\section{Acknowledgements}

I wish to thank the Arts and Humanities Research Council (AHRC), Nottingham Trent University and Cluny Lace for making this research possible. I also wish to thank the lace makers at Cluny Lace for sharing their time, expertise and insights with me about the work they do.

\section{Funding}

This work was supported by the Arts and Humanities Research Council (AHRC) [grant number AH/ K005952/1].

\section{Notes}


[1] Both IP and PS had extensive experience in the Leavers trade and exhibit 'technical variants' (Schangler 2005, 27 citing Pierre Lemonnier) in their working methods that differentiate Birkin workers' practice from Cluny workers'. While this dynamic is outside the scope of this article, it is explored in greater detail in Fisher and Botticello (forthcoming).

\section{References}

Anon. 2015. Nottingham lace. Accessed 8 August 2016. www.jigsawonline.com/blog/home/inside-cluny-lace.html

Banks, M. 2001. Visual Methods in Social Research. London: Sage.

Barthes, R. 2000. Camera Lucida. London: Vintage. Bazin, A. 1967. What Is Cinema, trans. Hugh Gray. Berkeley: University of California Press.

Bell, J. 2003. "Looking to See: Reflections on Visual Repatriation in the Purari Delta, Gulf Province, Papua New Guinea." In Museums and Source Communities, edited by L. Peers and A. Brown, 111-122. London: Routledge.

Bourdieu, P. 1990. The Logic of Practice. Translated Richard Nice. Cambridge: Polity Press.

Dilley, R. 2010. "Reflections on Knowledge Practices and the Problem of Ignorance." Journal of the Royal Anthropological Institute (NS) Special issue 16: S176-S192.

Dobres, M. A. 1999. "Technologies Links and Chaînes: The Processual Unfolding of Technique and Technician." In The Social Dynamics of Technology: Practice, Politics and World Views, edited by M. A. Dobres and C. R. Hoffman, 124-146. Washington, DC: Smithsonian Institution Press.

Edwards, E. 2003. "Introduction: Talking Visual Histories." In Museums and Source Communities, edited by L. Peers and A. Brown, 83-99. London: Routledge.

Edwards, E. 2005. "Photographs and the Sound of History." Visual Anthropology Review 21 (1-2): 27-46.

Favero, P. 2014. "Learning to Look Beyond the Frame: Reflections on the Changing Meaning of Images in the Age of Digital Media Practices." Visual Studies 29 (2): 166-179.

Fisher, T., and J. Botticello. Forthcoming. "Machine-Made Lace, the Spaces of Skilled Practice and the Paradoxes of Contemporary Craft Production." Cultural Geographies, Special Issue Forthcoming.

Haraway, D. 1998. “The Persistence of Vision.” In Visual Culture Reader, edited by N. Mirzoeff, 191-198. London: Routledge.

Herle, A. 2009. "John Layard long Malakula 19-14-1915: The Potency of Field Photography'." In Photography, Anthropology and History: Expanding the Frame, edited by C. Morton and E. Edwards, 241-263. Farnham: Ashgate Publishing. 
Jorgensen, L. B. 2013. "Introduction to Part II; Technology as Practice." In Embodied Knowledge: Historical Perspectives on Belief and Technology, edited by M. L. Stig Sorensen and K. Rebay-Salisbury, 91-94. Oxford: Oxbow Books.

Lave, J. 1996. “Teaching, as Learning, in Practice.” Mind, Culture and Activity 3 (3): 149164.

MacDougall, D. 2005. The Corporeal Image. Princeton: Princeton University Press.

Malafouris, L. 2004. "The Cognitive Basis of Material Engagement: Where Brain, Body and Culture Conflate." In Rethinking Materiality: The Engagement of Mind with the Material World, edited by E. DeMarrais, C. Gosden, and C. Renfrew, 53-62. Cambridge: McDonald Institute for Archaeological Research.

Martinón-Torres, M. 2002. “Chaîne Opératoire: The Concept and its Applications Within the Study of Technology." Gallaecia 21: 29-43.

Mauss, M. 2007. "Techniques of the Body." In Beyond the Body Proper, edited by M. Lock and J. Butler, 50-68. Durham: Duke University Press.

Mitchell, W. J. T. 2002. "Showing Seeing: A Critique of Visual Culture." Journal of Visual Culture 1 (2): 165-181.

Murray, S. 2008. "Digital Images, Photo-Sharing, and Our Shifting Notions of Everyday Aesthetics." Journal of Visual Culture 7 (2): 147-163.

Peers, L., and A. Brown. 2009. "Just by Bringing These Photographs. .. on the Other Meanings of Anthropological Images." In Photography, Anthropology and History: Expanding the Frame, edited by C. Morton and E. Edwards, 265-280. Farnham: Ashgate Publishing.

Pinney, C. 2002. "Visual Culture." In The Material Culture Reader, edited by V. Buchli, 8186. Berg: Oxford.

Pink, S. 2003. "Interdisciplinary Agendas in Visual Research: Resituating Visual Anthropology." Visual Studies 18 (2): 179-192.

Pink, S. 2007. “Walking with Video.” Visual Studies 22 (3): 240-252.

Pink, S. 2011. "Sensory Digital Photography: Re-Thinking "Moving" and Image." Visual Studies 26 (1): 4-13.

Pink, S. 2012. Advances in Visual Methodology. London: Sage Publications.

Ruby, J. 2000. Picturing Culture: Explorations of Film and Anthropology. Chicago: University of Chicago press.

Ryle, G. 1949. The Concept of Mind. London: Hutchinson. 
Sennett, R. 2008. The Craftsman. London: Allen Lane.

Schangler, N. 2005. "The Chaîne Opératoire." In Archaeology: The Key Concepts, edited by C. Renfrew and P. Bahn, 25-31. London: Routledge.

Schon, D. [1983] 1991. The Reflective Practitioner, How Professionals Think in Action. Aldershot: Ashgate Publishing.

Star, S. L. 1996. "Working Together: Symbolic Interactionism, Activity Theory and Information Systems." In Cognition and Communication at Work, edited by Y. Engstrom and D. Middleton, 296-318. Cambridge: Cambridge University Press.

Suchman, L. 1995. “Making Work Visible.” Communication of the ACM 38 (9): 57-64.

The Lacemakers: The Forgotten Story of English Lace. 2013. [DVD]. UK: Edward Jarvis.

Twisthands at the Deadstop. 2013. [Online media] UK www.youtube.com/watch?v=2mYtIPKmrwo

Woodward, S. 2008. "Digital Photography and ResearchRelationships: Capturing the Fashion Moment.” Sociology 42 (5): 857-872.

Wright, C. 2009. "Faletau's Photocopy, or the mutability of Visual History in Roviana." In Photography, Anthropology and History: Expanding the Frame, edited by C. Morton and E. Edwards, 223-239. Farnham: Ashgate Publishing.

von Manen, M. 2007. "Phenomenology of Practice." Phenomenology and Practice 1 (1): 11-30. 